\title{
The current status and the influencing factors of humanistic care ability among a group of medical professionals in Western China
}

\author{
Jing Deng, Lei Lei, Hui-Lan Zhang and Yu Luo* \\ School of Nursing, Third Military Medical University, Chongqing, China
}

Received 19 June 2018

Accepted 12 November 2018

\begin{abstract}
.
BACKGROUND: Previous research regarding the humanistic care ability of Chinese medical professionals was limited to small groups of nurses or students. More systemic analyses involving more general medical professionals are scarce and urgently needed.

OBJECTIVE: To survey the sense and ability of humanistic care on medical professionals in China and to identify the potential influencing factors.

METHODS: A novel scale of humanistic care indicators was developed. Based on the new scale, a questionnaire was designed, tested and used to survey a total of 928 medical professionals recruited from three hospitals in the Chinese Western city Chongqing. Chi-square test was used for single factor analyses. For multiple factor analyses, multivariate logistic regression was performed

RESULTS: Our selected group of medical professionals scored nearly 4 or above on a 1-5 scale for all our query items related to the sense and ability of humanistic care. The main factors affecting humanistic care ability of medical professionals in Chongqing include gender, nature of department/division, modes of employment and participation in humanistic care ability training and so on.

CONCLUSIONS: In general, the participants in our study group had a humanistic care ability score lower than the aimed value, suggesting that the ability of humanistic care of these medical professional was not satisfactory. The study also shows that one effective way to enhance the humanistic care ability is to provide more targeted training.
\end{abstract}

Keywords: Humanistic care, sense and ability, influencing factor, medical education

\section{Introduction}

The Global Minimum Education Requirements for medical professionals as proposed by the Core Committee of the International Institute for Medical Education in 2002 include seven minimum essential domains, namely, 1) professional values, attitudes, behavior and ethics, 2) scientific foundation of medicine, 3) clinical skills, 4) communication skills, 5) population health and health systems, 6) management of information and 7) critical thinking and research [1]. To make better connection between

\footnotetext{
${ }^{*}$ Corresponding author: Yu Luo, School of Nursing, Third Military Medical University, No. 30 Gaotanyan Street, Shapingba District, Chongqing 400038, China. Tel.: +86 15730142871; Fax: +86 23 68752351; E-mail: luoyuhlgl@tmmu.edu.cn.
}

0928-7329/19/\$35.00 (c) 2019 - IOS Press and the authors. All rights reserved

This article is published online with Open Access and distributed under the terms of the Creative Commons Attribution NonCommercial License (CC BY-NC 4.0). 
caring and love and human living processes, however, Jean Watson outlined 10 carative factors/caritas processes that include the development of humanistic-altruistic system of values, the development of helping-trusting human-caring relationship, the instillation and the enabling faith and hope, and the provision for a supportive, protective, and/or corrective mental, social, spiritual environment [2]. Going toward a direction of holistic caring, modern medical professionals are not only expected to provide the traditional medical caring to treat the diseased conditions, they are also expected to provide patientcentered humanistic caring by assisting the patients to seek their own value of life and achieve selfactualization and self-healing [3]. Studies have shown that the sense and ability of humanistic caring of medical professional is an important factor capable of influencing the psychological status, the treatment and the recovery of the patients. Meanwhile, humanistic caring is also of vital importance in improving the service levels and the customer satisfaction, the maintenance of a harmonious relationship between the medical professionals and the patients as well as the professional recognition among the medical professionals [4-7]. While the importance of humanistic caring in modern medicine is well recognized worldwide, the medical education sector faces a big challenge [8] of helping the medical professionals to develop the sense and ability of humanistic care. The term "sense of humanistic caring" here refers to the sound practical judgement of medical professionals concerning matters of humanistic caring. And the term "ability of humanistic caring" here refers to the ability of the medical professionals to provide humanistic caring for the patients.

To better prepare the medical professionals for the practice of humanistic care and to allow the synchronous development of medicine and medical humanities, medical humanities has been incorporated into the curriculum of medical education by the medical education sectors in many developed countries such as the United States and the United Kingdom as well as some Asian countries [9,10]. In China, advances in the study of the medical humanities and medical humanities education have been made over the past few decades. In comparison with its rapid economic development, however, the advancement in medical humanity education and medical humanity practice is relatively slow [11]. As a matter of fact, humanistic care training was virtually absent from the curriculum of medical education in most Chinese medical schools. Recently, a few studies were conducted to evaluate the ability of humanistic care among small groups of nurses and students in China $[12,13]$. A more systematic evaluation of the current status and the identification of the influencing factors of humanistic care, however, are still urgently needed.

In the current study, we developed a novel scale of humanistic care indicators, utilizing a Delphi technique. Based on the scale we have developed, we further designed a questionnaire and used it to survey the sense and ability of humanistic care in a relatively large group of medical professionals in Chongqing, a major Western Chinese city. The results are expected to allow better understanding of the current status of the sense and ability of humanistic care among the Chinese medical professionals and the identification of the influencing factors. The findings might also help the policy-makers and the medical educators to better design the medical educational programs.

\section{Materials and methods}

\subsection{Development of a scale for humanistic care indicators}

Following a literature review, colleague consultation, group discussions and two rounds of expert panel review, a preliminary set of humanistic care indicators was formulated using the Delphi technique [14-16]. The expert approval rates were $93.4 \%$ and $94.7 \%$ respectively in the first two rounds of expert review, with the mean of importance valuation being 4.4 and 4.5 respectively. The Kendall's 
$\mathrm{W}$ tests showed that the coordination coefficients in the first two rounds were both statistically significant $(p<0.01)$ [17]. In the third round of expert review, an analytic hierarchy process was used to rank the indicators, calculate the weight and to reach a consensus. The recovery rates of three rounds of expert review were 100, 93 and $100 \%$ respectively, with the expert authority coefficient being 0.9 . Focusing on respecting the dignity of life, sharing the decision making with the patients and assisting the patients with improving the quality of life and extending the duration of life with all the knowledge, passion and positive attitude of the medical professionals, this scale encompasses 4 dimensions (Respecting the independence of the personality and the initiative of the patients, Meeting the diagnostic and therapeutic needs of the patients, Meeting the special needs of the patients, Practicing humanistic care), 10 sub-dimensions and 37 indicators (see Appendix 1).

\subsection{Design and validation of the humanistic care questionnaire}

Based on the humanistic care indicators developed above, we further designed a questionnaire for the evaluation of the sense and the ability of humanistic care among medical professionals. The actual questionnaire consists of three parts. The first part contains an introduction explaining the study and its goals, in addition to a brief survey of the general personal information such as age, gender, education, marital status and whether has been trained with humanistic care courses and so on. The second part contains the scale for humanistic care that was largely based on the 37 indicators developed above. Certain indicators, however, were further split or expanded and certain indicators were combined, giving rise to a final of 42 query items, which included 8 items for the dimension of respecting the independence of the personality and the initiative of the patients, 11 items for the dimension of meeting the routine needs of the patients, 12 items for the dimension of meeting the special needs of the patients and 11 items for the dimension of practicing humanistic care (see Appendix 2). To ensure the validity of the questionnaire, 4 inverse questions were included. Each item is scored by a 1-5 Likert-type ranking. The higher the score, the better the sense and ability in humanistic care (see Appendix 3). In the preliminary tests, the overall Cronbach's $\alpha$ for the questionnaire was 0.93 and the dimensional Cronbach's $\alpha$ ranged between 0.93 and 0.95 , with a good internal consistency.

\subsection{The survey}

This study was approved by the Institutional Medical Ethics Committee of the Third Military Medical University. The investigators explained the purpose and the goals of the study but no hints or suggestions were given to the participants before the survey. The participants were also assured of the confidentiality of personal information.

A total of 1050 participants for the study were purposely recruited from three hospitals (Southwestern Hospital, Xinqiao Hospital and Daping Hospital) in the Chinese Western city Chongqing from various departments/divisions including the internal medicine, the surgery and the specialized medicine division (including departments such as Opthalmology, Stamotology, Plastics and Cosmetics), with each department/division having 15 medical professionals. The criteria for the enrollment were: 1) Being formally employed; 2) Having professional qualifications; 3) Knowing the purpose of the study and consenting on the study. The study was conducted between May and June 2017. Immediately before the survey, the investigators explained the purpose and the goals of the study and the questionnaire to the participants. A total of 1050 questionnaire forms and 1012 anonymously completed forms were returned, of which 928 were valid. The effective recovery rate thus was $91.7 \%$. 
Table 1

General characteristics of the participants $(n=928)$

\begin{tabular}{|c|c|c|c|}
\hline Variable & $n(\%)$ & Variable & $n(\%)$ \\
\hline Gender & & Division association & \\
\hline Male & $282(30.4)$ & Internal medicine & $197(21.2)$ \\
\hline Female & $646(69.6)$ & Surgery & $333(35.9)$ \\
\hline Age, y & & Specialized medicine division & $280(30.2)$ \\
\hline$<20$ & $7(0.8)$ & Medical technology division & $118(12.7)$ \\
\hline $20-29$ & $408(44.0)$ & Employment mode & \\
\hline $30-39$ & $428(46.1)$ & Tenured & $77(8.3)$ \\
\hline $40-49$ & $77(8.3)$ & Term-contracted & $851(91.7)$ \\
\hline$>50$ & $8(0.9)$ & Job duration & \\
\hline Education & & $<5$ & $365(39.3)$ \\
\hline Junior college & $152(16.4)$ & $6-10$ & 317 (34.2) \\
\hline Bachelor & $570(61.4)$ & $11-15$ & $154(16.6)$ \\
\hline Master & $206(22.2)$ & $16-20$ & $49(5.3)$ \\
\hline Professional title & & $\geqslant 21$ & $43(4.6)$ \\
\hline Physician & $374(40.3)$ & Training in life appreciation & \\
\hline Nurse & 463 (49.9) & Yes & $79(8.5)$ \\
\hline Technician & $74(8.0)$ & No & $849(91.5)$ \\
\hline Assistant & $17(1.8)$ & Training in humanistic care & \\
\hline Professional rank & & Yes & $95(10.2)$ \\
\hline Junior & $551(59.4)$ & No & $833(89.8)$ \\
\hline Intermediate & $322(34.7)$ & & \\
\hline Senior & $55(5.9)$ & & \\
\hline
\end{tabular}

\subsection{Data analyses}

Microsoft Excel 2007 and SPSS 19.0 were used for the data processing and analyses. The numerical data were expressed as mean $\pm \mathrm{SD}$. Pair-wise comparison was performed by the Student's $t$ test. Chi-square test was used for single factor analyses. For multiple factor analyses, multivariate logistic regression was performed. $p<0.05$ was considered to be statistically significant, $p<0.01$ and $p<$ 0.001 more so.

\section{Results}

\subsection{Participant characteristics}

The statistical analyses of 928 valid returns showed that the average age for the group of participants was $36.6 \pm 5.7$. Among the 928 participants, 282 were male $(30.4 \%)$ and 646 were female $(69.6 \%)$. Other characteristics are shown in Table 1.

\subsection{The self-assessed scores of the participants' humanistic care sense and ability}

Among the 42 query items, our selected group of medical professionals scored the highest on Item 24 (trying best to protect the privacy of the patients, $4.38 \pm 0.77$ ), Item 14 (trying best to avoid or minimize the pains or hurts to the patients throughout the process of diagnosis and treatment, 4.30 \pm 0.75 ) and Item 25 (trying best to create effective and loving communications with the patients and their family members, $4.27 \pm 0.81$ ). Meanwhile, our selected group of medical professionals scored the lowest on Item 40 (trying best to provide age and gender-based care, $3.99 \pm 0.92$ ), Item 41 (trying best 
Table 2

Self-assessed scores on the sense and ability of humanistic care among the selected group of medical professionals

\begin{tabular}{|c|c|c|c|c|c|}
\hline \multirow[t]{2}{*}{ Factors } & \multicolumn{5}{|c|}{ Dimensional and overall scores on the sense and ability of humanistic care (mean $\pm \mathrm{SD}$ ) } \\
\hline & $\mathrm{A}^{*}$ & B* & $\mathrm{C}^{*}$ & $\mathrm{D}^{*}$ & Overall \\
\hline \multicolumn{6}{|l|}{ Gender } \\
\hline Male & $4.25 \pm 0.62$ & $4.28 \pm 0.59$ & $4.23 \pm 0.63$ & $4.21 \pm 0.67$ & $4.25 \pm 0.59$ \\
\hline Female & $4.14 \pm 0.66$ & $4.14 \pm 0.63$ & $4.11 \pm 0.67$ & $4.08 \pm 0.72$ & $4.12 \pm 0.62$ \\
\hline$F$ & 0.082 & 0.820 & 0.132 & 0.958 & 0.291 \\
\hline$P$ & 0.000 & 0.002 & 0.014 & 0.010 & 0.002 \\
\hline \multicolumn{6}{|l|}{ Professional rank } \\
\hline Junior & $4.16 \pm 0.63$ & $4.15 \pm 0.59$ & $4.13 \pm 0.62$ & $4.13 \pm 0.64$ & $4.14 \pm 0.57$ \\
\hline Intermediate & $4.18 \pm 0.70$ & $4.19 \pm 0.66$ & $4.11 \pm 0.72$ & $4.06 \pm 0.81$ & $4.13 \pm 0.68$ \\
\hline Senior associate & $4.51 \pm 0.56$ & $4.48 \pm 0.57$ & $4.52 \pm 0.56$ & $4.45 \pm 0.58$ & $4.49 \pm 0.54$ \\
\hline Senior & $4.74 \pm 0.38$ & $4.71 \pm 0.30$ & $4.15 \pm 0.66$ & $4.12 \pm 0.71$ & $4.53 \pm 0.35$ \\
\hline$F$ & 6.200 & 6.099 & 6.159 & 4.328 & 5.934 \\
\hline$P$ & 0.000 & 0.000 & 0.000 & 0.005 & 0.001 \\
\hline \multicolumn{6}{|l|}{ Employment mode } \\
\hline Tenured & $4.51 \pm 0.54$ & $4.44 \pm 0.54$ & $4.43 \pm 0.61$ & $4.42 \pm 0.64$ & $4.44 \pm 0.55$ \\
\hline Term-contracted & $4.16 \pm 0.65$ & $4.16 \pm 0.62$ & $4.12 \pm 0.66$ & $4.09 \pm 0.71$ & $4.13 \pm 0.61$ \\
\hline$F$ & 2.957 & 1.137 & 0.338 & 0.624 & 0.314 \\
\hline$P$ & 0.000 & 0.000 & 0.000 & 0.000 & 0.000 \\
\hline \multicolumn{6}{|l|}{ Division association } \\
\hline Internal medicine & $4.44 \pm 0.57$ & $4.41 \pm 0.58$ & $4.32 \pm 0.62$ & $4.33 \pm 0.65$ & $4.37 \pm 0.57$ \\
\hline Surgery & $4.23 \pm 0.59$ & $4.24 \pm 0.53$ & $4.21 \pm 0.57$ & $4.17 \pm 0.61$ & $4.21 \pm 0.53$ \\
\hline Specialized medicine division & $4.02 \pm 0.73$ & $4.03 \pm 0.68$ & $3.99 \pm 0.73$ & $3.95 \pm 0.82$ & $3.99 \pm 0.70$ \\
\hline Medical technology division & $4.06 \pm 0.63$ & $4.03 \pm 0.62$ & $4.04 \pm 0.65$ & $4.05 \pm 0.68$ & $4.04 \pm 0.61$ \\
\hline$F$ & 18.609 & 19.064 & 12.763 & 12.573 & 17.328 \\
\hline$P$ & 0.000 & 0.000 & 0.000 & 0.000 & 0.000 \\
\hline \multicolumn{6}{|l|}{ Training in life appreciation } \\
\hline Yes & $4.56 \pm 0.55$ & $4.47 \pm 0.58$ & $4.45 \pm 0.59$ & $4.46 \pm 0.58$ & $4.48 \pm 0.54$ \\
\hline No & $4.15 \pm 0.65$ & $4.16 \pm 0.62$ & $4.12 \pm 0.66$ & $4.09 \pm 0.71$ & $4.13 \pm 0.61$ \\
\hline$F$ & 1.653 & 0.222 & 0.698 & 1.832 & 0.814 \\
\hline$P$ & 0.000 & 0.000 & 0.000 & 0.000 & 0.000 \\
\hline \multicolumn{6}{|l|}{ Training in humanistic care } \\
\hline Yes & $4.55 \pm 0.54$ & $4.46 \pm 0.56$ & $4.44 \pm 0.58$ & $4.43 \pm 0.62$ & $4.46 \pm 0.55$ \\
\hline No & $4.15 \pm 0.65$ & $4.15 \pm 0.62$ & $4.11 \pm 0.66$ & $4.09 \pm 0.71$ & $4.12 \pm 0.61$ \\
\hline$F$ & 1.693 & 0.872 & 0.991 & 0.599 & 0.529 \\
\hline$P$ & 0.000 & 0.000 & 0.000 & 0.000 & 0.000 \\
\hline
\end{tabular}

*A, the dimension of respecting the independence of the personality and the initiative of the patients; $\mathrm{B}$, the dimension of meeting the diagnostic and therapeutic needs of the patients; $C$, the dimension of meeting the special needs of the patients; $D$, the dimension of practicing humanistic care.

to provide region-based, nationality-based and religion-based care, $3.99 \pm 0.93$, and Item 29 (Trying best to mobilize social support for the patients, $4.00 \pm 0.93$ ). Some important dimensional and overall scores on the sense and ability of humanistic care of the selected group of medical professionals are as tabulated in Table 1. Further, those from the division of Internal Medicine scored a higher overall score $(4.37 \pm 0.57, n=197)$ than those from other divisions, and those tenured participants $(4.44 \pm 0.55, n=$ $77)$ also scored a higher overall score $(4.13 \pm 0.61, n=851)$ than those term-contracted participants. Moreover, the male participants scored a higher overall score $(4.25 \pm 0.59, n=282)$ than the female participants $(4.12 \pm 0.62, n=646)$. Also noteworthy is that previous training in both life appreciation (4.48 $\pm 0.54, n=79$ for those with previous training in life appreciation versus $4.13 \pm 0.61, n=$ 849 for those did not) and humanistic care $(4.46 \pm 0.55, n=95$ for those with previous training in humanistic care versus $4.12 \pm 0.61, n=833$ for those did not) appeared to be helpful in enhancing the sense and ability of humanistic care among our selected group of medical professionals. 
Table 3

Multivariate regression analyses on the sense and ability of humanistic care among the selected group of medical professionals $(n=928)$

\begin{tabular}{|c|c|c|c|c|c|}
\hline Factors & B & SE & $\beta$ & $t$ & $p$-value \\
\hline Constant & 4.383 & 0.054 & - & 80.803 & 0.000 \\
\hline Division association & -0.127 & 0.020 & -0.196 & -6.203 & 0.000 \\
\hline Training in humanistic care & 0.271 & 0.065 & 0.133 & 4.146 & 0.000 \\
\hline Employment mode & 0.215 & 0.073 & 0.096 & 2.949 & 0.003 \\
\hline Gender & 0.085 & 0.043 & 0.064 & 1.972 & 0.049 \\
\hline
\end{tabular}

$\mathrm{B}$, unstandardized coefficient; SE, standard error of the unstandardized coefficient; $\beta$, standardized coefficient; $t$, validity coefficient of the regression.

\subsection{Single factor analyses of factors that might affect the sense and ability of humanistic care among the medical professionals}

Single factor analyses were performed with categories of the general information of the participants. The results identified gender, professional rank, employment mode, division association, training in life appreciation and training in humanistic care as factors that might influence the sense and ability of humanistic care among the selected group of medical professionals $(p<0.05$, Table 2$)$. Other categories including age, marital status, education, duration in job and professional title did not appear to be potential influencing factors.

\subsection{Multivariate regression analyses of factors that might affect the sense and ability of humanistic care among the medical professionals}

We performed multivariate regression analyses using the potential influencing factors identified by the single factor analyses described above. The results largely confirmed the finding of single factor analyses. Gender, employment mode, division association, and training in humanistic care were all shown to be potential factors that might influence the sense and ability of humanistic care among the selected group of medical professionals $\left(R^{2}=0.08, F=20.95, p=0.000\right.$, Table 3$)$, with the exception of professional rank and training in life appreciation.

\section{Discussion}

The original intention and the essence of medicine are to serve life, through extending sympathy, respect and empathy to all individuals and with the ultimate goal of maintaining the health of all individuals [18]. As suggested, humanistic care is characterized by a respectful and compassionate relationship between all members of the health-care team, and their patients and family members [19]. Humanistic care is not simply to meet the clinical needs of the patients, it requires the medical professionals to pursue the excellence in many aspects of caring, especially with the spiritual, philosophical, ethical and moral dimensions [20].

Practicing humanistic care requires altruism, integrity, and empathy, as well as a dedication to service and sensitivity to the values and backgrounds of the patients [21]. The practice of humanistic care by the medical professionals through extending respect, understanding, sympathy and empathy to the patients on one hand might be very helpful in patient's fight with the diseases. On the other hand, it will also be helpful in the mutual understanding and the maintenance of a harmonious relationship between the medical professionals and the patients [22], which appears to be of particular importance in China 
currently. A systematic understanding of the current status of the sense and ability of humanistic care of the medical professionals is thus of vital importance in this country.

In previous studies investigating the humanistic care ability of medical professionals in China, a scale named Caring Ability Inventory (CAI), originally developed by Nkongho [21], was often used to measure an individual's ability to care when involved in a relationship with others [23-26]. The CAI consists of 37 items, grouped under three sub scales: Knowing (CAI_K; 14 items), Courage (CAI_C; 13 items), and Patience (CAI_P; 10 items) [24]. The CAI scores were derived based on a 1-7 Likert-type ranking, with the range of the scores being 37-259 and the higher the scores, the higher the caring ability. In a later study using CAI, Watson proposed that those scored at the $85^{\text {th }}$ percentile or higher $(\geqslant 220)$ being can be regarded as having good humanistic care ability and those at the $78^{\text {th }}$ percentile or lower ( $\leqslant$ 202) being as having poor humanistic care ability [27]. These Chinese studies, however, suffered from a number of the limitations including small groups of nurses or students.

In the current study, we have developed a new set of humanistic care indicators and a new questionnaire that differs from the CAI scale in many ways including query content, query items and query numbers. Our new set of humanistic care indicators consists of 42 items, grouped under four dimensions, namely, Respecting the independence of the personality and the initiative of the patients, Meeting the diagnostic and therapeutic needs of the patients, The special needs of the patients and Practicing humanistic care. Further, the scores were ranked by a 1-5 Likert-type ranking instead of a 1-7 Likerttype ranking, with the ranges of the scores being 42-210. For these reasons, it is therefore difficult for us to compare the scores of our study directly with those conducted with the CAI scale. Considering these limitations, the only thing we can do is calibrate our scores with the highest expectation of the scale, that is, the highest possible score of 5 , taking into the account of the $85^{\text {th }}$ percentile adopted in the CAI scale [25]. We therefore consider those scored 4.25 or higher $\left(85^{\text {th }}\right.$ percentile or above $)$ as having good humanistic care ability and those scored 3.9 or lower $\left(78^{\text {th }}\right.$ percentile or lower) as having poor humanistic care ability.

In the current study, we found that our selected group of participants scored nearly 4 or above in all the queried items, suggesting that this group of medical professionals mostly have certain levels of the sense of humanistic care and are probably competent in practicing it, although not satisfactory. In particular, our selected group of participants scored relatively high on Items 14, 24 and 25, suggesting that this group of medical professionals more likely will try their best to avoid or minimize the pains or hurts to the patients throughout the process of diagnosis and treatment, to protect the privacy of the patients and to create effective and loving communications with the patients and their family members [28]. Multivariate regression analyses of factors that gender, employment mode, division association, and training in humanistic care were all shown to be potential factors that might influence the sense and ability of humanistic care among the selected group of medical professionals.

Surprisingly, male participants scored a higher overall score on the ability of humanistic care than the female participants, which is in conflict with a previous finding that female medical students scored a higher overall score on the ability of humanistic care than male medical students [25]. The reason for male participants scored a higher overall score on the ability of humanistic care than the female participants in current study is not completely clear right now but this probably has something to do with the fact that there were much more females (646) than males (282) among our participants. In China in general and in the current study, the nurses were mostly females and the doctors were mostly males. Since in general nurses were given relatively less responsibility and powers in dealing with matters related to patient care than the doctors, this might result in the lack of motive and power in providing humanistic care to the patients among the nurses. In our view, this at least in part explain why male participants scored a higher overall score on the ability of humanistic care than the female participants. 
Similarly, we found that the mode of employment appeared to affect the sense and ability of humanistic care significantly among the selected group of medical professionals. This on one hand could be due to the bias that those tenured (permanent, 77) were much less than those term-contracted (temporary, 851). It is well known that in China the permanent employees are more advantageous than the term-contracted employees in many ways including the salary compensation, the promotion and the life insurance. These discrepancies to a certain degree might affect the attitude and enthusiasm and performance of the termcontracted employees. Fortunately, with current on-going reform on the human resource regulations in Chinese hospitals, more medical professionals will be employed via the tenure track system, which might be helpful in the promotion of the practice of humanistic care among the medical professionals.

Importantly, our results (Table 2) show that those participants received either training in life appreciation or training in humanistic care invariably scored higher scores on the dimension of respecting the independence of the personality and the initiative of the patients, the dimension of meeting the diagnostic and therapeutic needs of the patients, the dimension of meeting the special needs of the patients and the dimension of practicing humanistic care as well as the overall scores than those did not, suggesting these trainings appeared to be effective in the promotion of the practice of humanistic care. Also noteworthy is that seniority also appeared to results in higher scores. Together these results, to a certain degree, seem to suggest the feasibility of improving the humanistic care ability of medical professionals through proper training.

Overall, to better prepare the medical professionals for the practice of humanistic care in China, systemic efforts from both the hospitals and the medical professions themselves probably will be needed $[29,30]$. For example, training in humanism and humanistic care should probably be included into the formal curriculum of medical education or in the continuing medical educational programs. The practice of humanistic care should also be considered to be included the evaluation systems of the medical professionals. Meanwhile, more training should be provided to encourage all medical professionals to enhance the awareness and self-motivation and capability in the practice of patient-center humanistic care.

\section{Conclusions}

This systemic study found that the humanistic care ability of Chinese medical professionals needs to be improved. It also shows that the main factors affecting the humanistic caring ability of Chinese medical professionals include gender, nature of the department, employment modes and humanistic care ability training of relevant experience. Most importantly, targeted trainings appear to be very effective in improving the humanistic care ability among Chinese medical workers or medical professionals.

\section{Acknowledgments}

The authors thank the consulting experts for the research design. They also appreciate the assistance of two graduate students in the College of Nursing, and the participants of the surveys from three hospitals for their assistance and cooperation in the project. The research was supported by the Chongqing Higher Education Teaching Reform Project (162062), the Third Military Medical University Humanities and Social Science Fund Project (2015XRW06) and the Third Military Medical University Teaching Reform Project (2014B08). 


\section{Conflict of interest}

None to report.

\section{References}

[1] Schwarz MR, Wojtczak A. Global minimum essential requirements: A road towards competence-oriented medical education. Med Teach 2002; 24(2): 125-129. doi: 10.1080/01421590220120740.

[2] Watson J. Watson's theory of human caring and subjective living experience: carative factors/caritas processes as a disciplinary guide to the professional nursing practice. Texto and Contexto Enferm 2007; 16(1): 129-135. doi: 10.1590/9010407072007000100016.

[3] Watson J. Love and caring ethics of face and hand-an invitation to return to the heart and soul of nursing and our deep humanity. Nurs Adm Q 2003; 27(3): 197-202.

[4] Borreani C, Miccinesi G. End of care preferences. Curr Opin Support Palliat Care 2008; 2(1): 54-59. doi: 10.1097/SPC. 0b013e3282f4cb27.

[5] Nagamatsu Y, Natori Y, Yanai H, Horiuchi S. Impact of a nursing education program about caring for patients in Japan with malignant pleural mesothelioma on nurses' knowledge, difficulties and attitude: A randomized control trial. Nurse Educ Today 2014; 34(7): 1087-1093. doi: 10.1016/j.nedt.2014.02.007.

[6] Shiau SJ, Chen CH. Reflection and critical thinking of humanistic care in medical education. Kaohsiung J Med Sci 2008; 24(7): 367-372. doi: 10.1016/s1607-551x(08)701134-7.

[7] Wu HL, Volker DL. Humanistic nursing theory: Application on to hospice and palliative care. J Adv Nurs 2012; 68(2): 471-479. doi: 10.1111/j.1365-2648.2011.05770.x.

[8] Chen YY, Wang WD, Leung KK. Some thoughts about medical humanities education. J Med Educ 2011; 15(3): $215-221$.

[9] Lv QB, Liu X, Shao QX, Li PP, Chen X. Investigation and contrastive analysis on the situation of the medical humanistic education in medical universities. Chinese Medical Ethics 2015; 28(6): 986-989.

[10] Song P, Tang W. Emphasizing humanities in medical education: Promoting the integration of medical scientific spirit and medical humanistic spirit. Biosci Trends 2017; 11(2): 128-133. doi: 10.5582/bst.2017.01092.

[11] Tang W. Propelling medical humanities in china. Biosci Trends 2017; 13(2): 125-127.

[12] Fei DX, Sheng LJ, Peng DZ, Peng KL, Zhao LP. Research progress of nurses' humanistic care ability and its influencing factors in China. Chinese General Practice Nursing 2017; 15(12): 1429-1432. doi: 10.3969/j.issn.1674-4748.2017. 012.007.

[13] Wen Y, Li M, Zhang D. Effect of humanistic care training for nurses caring ability and sense of meaning of life. Lab Med Clin 2017; 14(13): 1989-1992. doi: 10.3969/j.issn.1672-9455.2017.13.061.

[14] Twiss BC. The Delphi method - techniques and applications. Linstone A, Turoff M. eds. Addison-Wesley, Reading, Mass. Long Range Planning. 1976; 9(4): 94-95. doi: 10.1016/0024-6301(76)90044-3.

[15] Njuangang S, Liyanage C, Akintoye A. Application of the Delphi technique in health care maintenance. International Journal of Health Care Quality Assurance 2017; 30(8): 737-754. doi: 10.1108/IJHCQA-02-2017-0042.

[16] Jacob E, Duffield E, Jacob D. A protocol for the development of a critical thinking assessment tool for nurses using a Delphi technique. Journal of Advanced Nursing 2017; 73(8): 1982-1988. doi: 10.1111/jan.13306.

[17] Ye BR, Jiang XY. Study of an evaluation index system of nursing undergraduate employability developed using the Delphi method. Int J Nurs Sci 2014; 1(2): 180-184. doi: 10.1016/j.ijnss.2014.05.018.

[18] Li PP. Life education practice in medical colleges and universities. Chinese Medical Ethics 2015; 28(3): 474-476.

[19] Arnold P. Gold foundation. FAQs-What is humanism in healthcare? http://www.gold-foundation.org/about-us/faqs/ (accessed November 12, 2017).

[20] Calle GH, Martin MC, Nin N. Seeking to humanize intensive care. Rev Bras Ter Intensiva 2017; 29(1): 9-13. doi: 10.5935/0103-507x.20170003.

[21] Chang Y, Zhou X, Zhang F. Medical humanity: How do we learn it? Chin Med J (Engl) 2014; 127(24): 4292-4294. doi: 10.3760/cma.j.issn.0366-6999.20141292.

[22] Hou X, Xiao L. An analysis of the changing doctor-patient relationship in China. J Int Bioethique 2012; 23(2): 83-94, 177-178. doi: 10.3917/jib.232.0083.

[23] He J, Hu DY, Liu YL, Wu LF, Liu L. Study of the effect of humanistic nursing care model wards in Children Caring Ward School on the nurses' caring ability. Chinese Nursing Research 2016; 3(1): 45-47. doi: 10.1016/j.cnre.2016.04.001.

[24] Cheng L, Liu YL, Ke YY, Wang WR. Comparison of caring ability between Chinese and American nursing students. Western Journal of Nursing Research 2017; 9(2): 290-304. doi: 10.1177/0193945916656613.

[25] Ge XH, Li JS, Chen HY, Shao XH, Tang H, Wu P. Analysis of humanistic care ability of medical students and its influencing factors. Journal of Shanghai Jiao Tong University Medical Science 2014; 34(11): 1672-1677. doi: 11.3969/ j.issn.1674-8115.2014.11.023. 
[26] Xu J, Liu YL. Investigation and analysis of nursing staff's caring ability. Journal of Nursing Research 2008; 23(3): 16-18.

[27] Watson J. Assessing and Measuring Caring in Nursing and Health Sciences. New York: Springer Publishing Co; 2008. p. 117-124.

[28] Lee I, Wang HH. Preliminary development of humanistic care indicators for residents in nursing homes: A Delphi technique. Asian Nurs Res 2014; 8(1): 75-81. doi: 10.1016/j.anr.2014.03.001.

[29] Jiang P. A discussion about the humanistic care in college's education management work. Cross-Cultural Communication 2014; 10(3): 72-76. doi: 10.496814656.

[30] Vogel RI, Strayer LG, Ahmad RL, Blaes A, Lazovich D. A qualitative study of quality of life concerns following a melanoma diagnosis. J Skin Cancer 2017; 2017: 1-8. doi: 10.1155/2017/2041872.

\section{Appendix 1}

A scale for the indicators of the sense and ability of humanistic care among medical professionals.

\begin{tabular}{|c|c|c|}
\hline $\begin{array}{c}\text { Dimension } \\
\text { (primary) }\end{array}$ & $\begin{array}{l}\text { Sub-dimension } \\
\text { (secondary) }\end{array}$ & Indicator (tertiary) \\
\hline $\begin{array}{l}\text { A Respecting the } \\
\text { independence of } \\
\text { the personality } \\
\text { and the initiative } \\
\text { of the patients }\end{array}$ & $\begin{array}{l}\text { A1 Respecting the } \\
\text { independence of the } \\
\text { patients and their } \\
\text { family members }\end{array}$ & $\begin{array}{l}\text { A11 Encouraging the patients to fully express their felling and emotion } \\
\text { A12 Encouraging the patients to question about their illness and the treatment } \\
\text { A13 Considering and adopting the opinions and suggestions from the patients and } \\
\text { their family members }\end{array}$ \\
\hline
\end{tabular}

A2 Enhancing the A21 Assisting the patients with correct understanding of their illness and health ability of self-care of problems

the patients $\quad A 22$ Helping the patients with the formulation of self-care

A23 Helping the patients with the practice of self-care

$B$ Meeting the diagnostic and therapeutic needs of $B 1$ Meeting the med- $B 11$ Being kind, friendly, compassionate and loving to every patient the patients ical service needs of the patients

$B 12$ Explaining the status of the illness and the treatment plan in a way easy to understand by the patients

$B 13$ Discussing the charges in details and providing receipts to the patients $B 14$ Being cost effective and trying best to avoid excessive treatment

$B 2$ Meeting the med- $B 21$ Obeying the procedures of diagnosis and treatments strictly ical needs of the pa- $B 22$ Avoiding or minimizing the pains or hurts to the patients throughout the tients process of diagnosis and treatment $B 23$ Trying best to formulate a optimal therapeutic protocol

$B 24$ Paying attention to the progression of the illness and dealing with it in a timely manner

$B 25$ Trying best to avoid unnecessary hurts and to sustain life

$B 26$ Trying best to improve the quality of life for the patients

$C$ Meeting the special needs of the patients
C1 Meeting the phy- $C 11$ Trying best to alleviate the un-comfort or pain of the patients in a timely siological needs of manner the patients

C12 Trying best to meet the needs for nutrition, resting, sleeping and exercise

C13 Trying best to create a comfortable, safe and convenient environment

$C 2$ Meeting the psy- $C 21$ Trying best to protect the privacy of the patients

chological needs of $C 22$ Trying best to create effective and loving communications with the patients the patients and their family members

C23 Trying best to earn the trust from the patients and their family members C24 Trying best to assist with the adaptation and to alleviate the negative feeling or psychological burden of the patients

C3 Meeting the soci- C31 Advising the patients with ways and methods of seeking help from the proetal needs of the pa- fessionals or the society

tients C32 Paying attention to the emotional status and the effects of the social relations C33 Encouraging the interactions between the patients and their family members 


\begin{tabular}{|c|c|c|}
\hline $\begin{array}{l}\text { Dimension } \\
\text { (primary) }\end{array}$ & $\begin{array}{l}\text { Sub-dimension } \\
\text { (secondary) }\end{array}$ & Indicator (tertiary) \\
\hline \multirow[t]{7}{*}{$\begin{array}{l}D \text { Practicing hu- } \\
\text { manistic care }\end{array}$} & $\begin{array}{l}\text { D1 Enhancing your } \\
\text { empathy through as- } \\
\text { suming yourself be- } \\
\text { ing a patient instead } \\
\text { of a doctor }\end{array}$ & $\begin{array}{l}\text { D11 Sensing the emotional changes of the patients in a timely manner } \\
\text { D12 Understanding the circumstantial and emotional alterations D13 Encourag- } \\
\text { ing the patients and their family members to have the confidence in the fight with } \\
\text { the illness }\end{array}$ \\
\hline & $\begin{array}{l}\text { D2 Encouraging the } \\
\text { patients mobilize }\end{array}$ & $\begin{array}{l}D 21 \text { Encouraging the patients to seek for the spiritual sustenance that will be } \\
\text { helpful with the recovery }\end{array}$ \\
\hline & their potentials & $\begin{array}{l}\text { D22 Encouraging the companion support during the treatment and the recovery } \\
\text { D23 Providing the platform for communication among the patients } \\
\text { D24 Encouraging the mutual understanding and love between the patients and } \\
\text { their family members }\end{array}$ \\
\hline & $\begin{array}{l}\text { D3 Providing indi- } \\
\text { vidualized care }\end{array}$ & $\begin{array}{l}\text { D31 Respecting the culinary habits, values, the traditions and the taboos of the } \\
\text { patients }\end{array}$ \\
\hline & & D32 Providing age and gender-based care \\
\hline & & D33 Providing region-based, nationality-based and religion-based care \\
\hline & & itution-based care \\
\hline
\end{tabular}

\section{Appendix 2}

\section{The correspondence of 37 indicators and 42 query items.}

A11 Encouraging the patients to fully express their felling
and emotion
A12 Encouraging the patients to question about their ill-
ness and the treatment
A13 Considering and adopting the opinions and sugges-
tions from the patients and their family members
A21 Assisting the patients with correct understanding of
their illness and health problems

A22 Helping the patients with the formulation of self-care A23 Helping the patients with the practice of self-care

B11 Being kind, friendly, compassionate and loving to every patient

$B 12$ Explaining the status of the illness and the treatment plan in a way easy to understand by the patients

$B 13$ Discussing the charges in details and providing receipts to the patients

$B 14$ Being cost effective and trying best to avoid excessive treatment

$B 21$ Obeying the procedures of diagnosis and treatments strictly

B22 Avoiding or minimizing the pains or hurts to the patients throughout the process of diagnosis and treatment $B 23$ Trying best to formulate a optimal therapeutic protocol

B24 Paying attention to the progression of the illness and dealing with it in a timely manner
1 Trying best to encourage the patients and the family members to fully express their felling and emotion

2 Trying best to encourage the patients to question about their illness and the treatment and trying best to endorse their selections of treatments

3 Trying best to consider and adopt the opinions and suggestions from the patients and their family members

4 Trying best to assist the patients with correct understanding of their immediate illness

5 Trying best to assist the patients with correct understanding of other health problems

6 Trying best to help the patients with the formulation of self-care 7 Trying best to help the patients with the practice of self-care 8 Trying best to help the patients with other activities

9 Being kind, friendly, compassionate and loving to every patient

10 Trying best to explain the status of the illness and the treatment plan in a way easy to understand by the patients

11 Trying best to discuss the charges in details and providing receipts to the patients

12 Being cost effective and being able to avoid excessive treatment

13 Trying best to obey the procedures of diagnosis and treatments strictly

14 Trying best to avoid or minimize the pains or hurts to the patients throughout the process of diagnosis and treatment

15 Trying best to formulate a optimal therapeutic protocol

16 Trying best to observe the irregularities of the patients and making the accurate judgment

17 Being sensitive to clinical situations and able to deal with them in a timely and decisive manner

18 Being experienced in clinical emergencies 
B25 Trying best to avoid unnecessary hurts and to sustain 19 Trying best to avoid unnecessary hurts and in sustaining life life and improving the quality of life for the patients

B26 Trying best to improve the quality of life for the patients

C11 Trying best to alleviate the un-comfort or pain of the patients in a timely manner

20 Trying best to alleviate the un-comfort or pain of the patients in a timely manner

C12 Trying best to meet the needs for nutrition, resting, 21 Trying best to meet the needs for nutrition, resting, sleeping sleeping and exercise and exercise of the patients

C13 Trying best to create a comfortable, safe and convenient environment

22 Trying best to make the patients to feel comfortable

C21 Trying best to protect the privacy of the patients 23 Trying best to create a safe and convenient environment $\begin{array}{ll}\text { cations with the patients and their family members } & 25 \text { Trying best to create effective and lovity } \\ \text { the patients and their family members }\end{array}$

C23 Trying best to earn the trust from the patients and 26 Trying best to earn the trust from the patients and their family their family members members

C24 Trying best to assist with the adaptation and to alle- 27 Trying best to assist with the physiological adaptation and to viate the negative feeling or psychological burden of the patients

alleviate the negative feeling or psychological burden of the patients

C31 Advising the patients with ways and methods of 28 Trying best to advise the patients with ways and methods of seeking help from the professionals or the society seeking help from the professionals or the society

C32 Paying attention to the emotional status and the ef- 29 Trying best to mobilize social support for the patients fects of the social relations

C33 Encouraging the interactions between the patients and their family members

30 Trying best to encourage the interactions between the patients and their family members

31 Trying best to encourage the interactions between the patients and the society

D11 Sensing the emotional changes of the patients in a 32 Trying best to understand the psychological and emotional timely manner needs of the patients

D12 Understanding the circumstantial and emotional al- 33 Trying best to understand the circumstantial and emotional alterations terations

D13 Encouraging the patients and their family members 34 Trying best to encourage the patients and their family members to have the confidence in the fight with the illness D21 Encouraging the patients to seek for the spiritual sustenance that will be helpful with the recovery D22 Encouraging the companion support during the treatment and the recovery

D23 Providing the platform for communication among the patients

D24 Encouraging the mutual understanding and love between the patients and their family members

D31 Respecting the culinary habits, values, the traditions and the taboos of the patients

D32 Providing age and gender-based care to have the confidence in the fight with the illness

35 Trying best to encourage the patients to seek for the spiritual sustenance that will be helpful with the recovery

36 Trying best to encourage the companion support during the treatment and the recovery

37 Trying best to provide the platform for communication among the patients

38 Trying best to encourage the mutual understanding and love between the patients and their family members

D33 Providing region-based, nationality-based and 41 Trying best to provide region-based, nationality-based and religion-based care

D34 Providing institution-based care

39 Trying best to respect the culinary habits, values, the traditions and the taboos of the patients

40 Trying best to provide age and gender-based care

42 Trying best to provide institution-based care

\section{Appendix 3}

A questionnaire regarding humanistic care among medical professionals (translated from a Chinese version)

May 22, 2017

Dear sir,

We are conducting a research project regarding the sense and the ability of humanistic care among medical professionals in China. This project was supported in part by Humanity and Social Sciences Fund (2015XRW06) from the Third Military Medical University, Chongqing, China. 
The goals of this project include the setting-up of a practical scale for the indicators of humanistic care among medical professionals and the evaluation of the current status of the practice of humanistic care in medical institutions, utilizing the scale. The results are expected to allow better understanding of the sense and the ability of humanistic care among Chinese medical professionals as well as the identification of the influencing factors. To ensure the validity of the investigation, please complete the attached questionnaire as accurate and truthfully as possible and we guaranteed that the information will be kept as confidential and private and used solely for the research purpose.

Thank you very much for your cooperation and assistance!

Yu Luo, Professor of Nursing

Jing Deng, Research assistant

Part 1 General Information (Please check the items that apply, give explanation if necessary)

A. Gender: Male Female

B. Age (years): $\leqslant 20 \quad 21-29 \quad 30-39 \quad 40-49 \geqslant 50$

$C$. Education: Junior college Bachelor's Master's Doctoral degree

$D$. Professional title: Physician Nurse Technician Assistant

$E$. Division: Internal medicine Surgery Specialized medicine Medical technology

$F$. Employment mode: Permanent Term-contracted

$G$. Duration in job (years): $\leqslant 5 \quad 6-10 \quad 11-15 \quad 16-20 \geqslant 21$

$H$. Professional rank: Junior Intermediate Senior associate Senior

I. Participation in life appreciation: Yes (explain if yes) No

$J$. Participation in humanistic care training: Yes (explain if yes) No

Part 2 The sense and ability in humanistic care. All items are rated by a five-point Likert-type scale, with the core 5 being the best practice and the score 1 being the poorest practice in the humanistic care. Please select a score that best describe your performance for each of the 42 items in the table.

\begin{tabular}{l}
\hline Item \\
\cline { 2 - 2 } \\
\hline 1 Trying best to encourage the patients and the family members to fully express their felling and emotion \\
2 Trying best to encourage the patients to question about their illness and the treatment and trying best to \\
endorse their selections of treatments \\
3 Trying best to consider and adopt the opinions and suggestions from the patients and their family \\
members \\
4 Trying best to assist the patients with correct understanding of their immediate illness \\
5 Trying best to assist the patients with correct understanding of other health problems \\
6 Trying best to help the patients with the formulation of self-care \\
7 Trying best to help the patients with the practice of self-care \\
8 Trying best to help the patients with other activities \\
9 Being kind, friendly, compassionate and loving to every patient \\
10 Trying best to explain the status of the illness and the treatment plan in a way easy to understand by \\
the patients \\
11 Trying best to discuss the charges in details and providing receipts to the patients \\
12 Being cost effective and being able to avoid excessive treatment \\
13 Trying best to obey the procedures of diagnosis and treatments strictly \\
14 Trying best to avoid or minimize the pains or hurts to the patients throughout the process of diagnosis \\
and treatment \\
15 Trying best to formulate a optimal therapeutic protocol \\
16 Trying best to observe the irregularities of the patients and making the accurate judgment \\
17 Being sensitive to clinical situations and able to deal with them in a timely and decisive manner
\end{tabular}




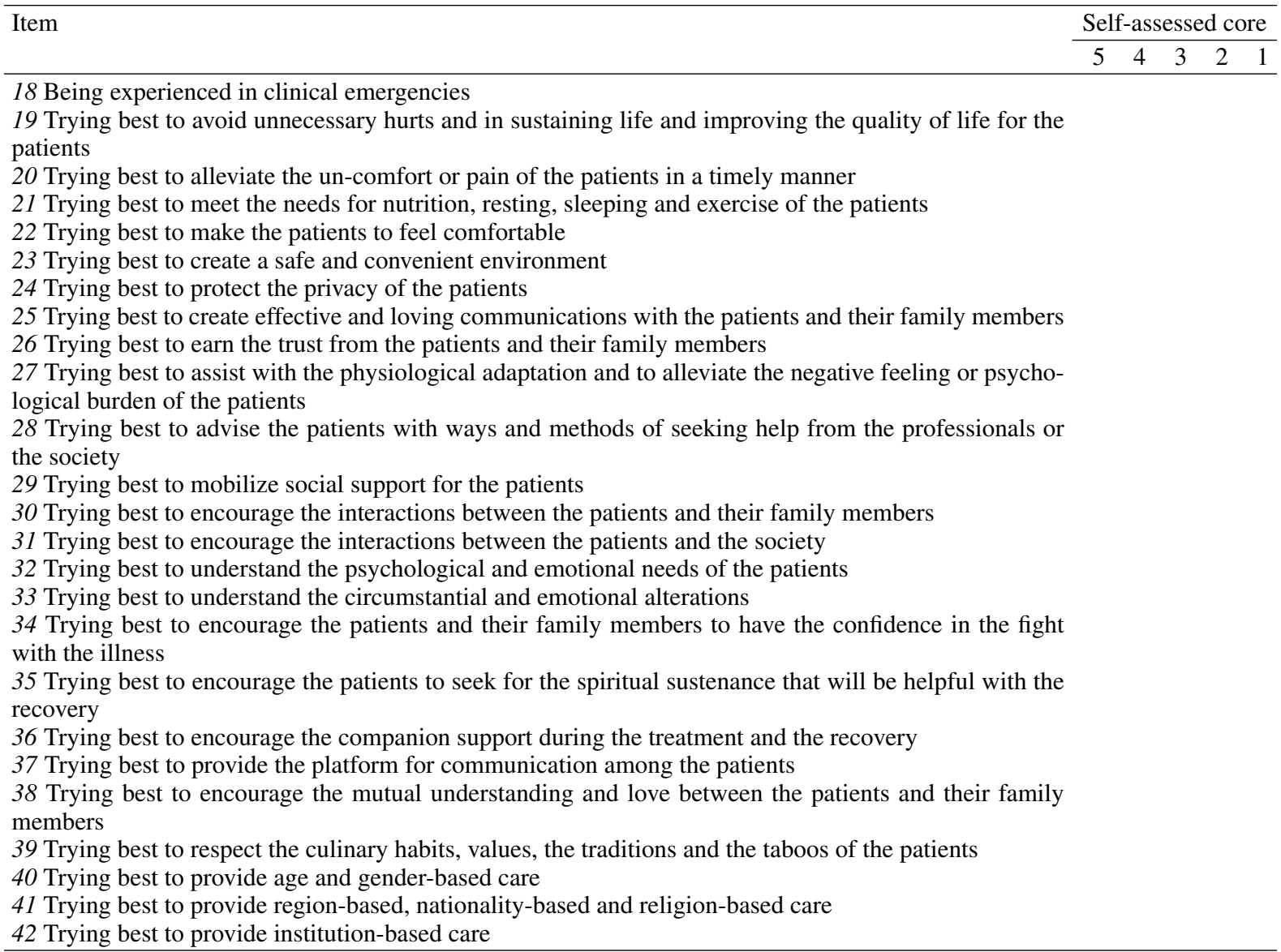

\section{Part 3 Your suggestions regarding humanistic care?}

